\title{
Turismo taurino como estrategia de conservación para un patrimonio en riesgo: El caso de las ganaderías de toros de lidia en Tlaxcala, México.
}

\author{
Serafín Ríos Elorza* \\ El Colegio de Tlaxcala, A.C (México)
}

\begin{abstract}
Resumen: En México, la crianza de toros de lidia surge a finales del siglo XIX. Tlaxcala es el estado mexicano con el mayor número de ganaderías. La cultura taurina muestra su arraigo en sus ganaderías, plazas de toros, toreros, escuelas taurinas y corridas de toros. Actualmente los ganaderos enfrentan severos problemas financieros, debido a elevados costos de producción, al oneroso mantenimiento de inmuebles y disminución de eventos, debido al activismo de grupos anti taurinos. Lo anterior ha provocado cierre de ganaderías con repercusiones sociales, económicas, ambientales y patrimoniales. Esta investigación analiza las perspectivas que tiene el turismo taurino, para erigirse en un medio que permita al turista conocer la cultura taurina como un proceso que trasciende la polémica fiesta brava, al tiempo de generar ingresos que garanticen la conservación de este patrimonio. La metodología consideró revisión documental histórica y observación participante con entrevistas a profundidad.
\end{abstract}

Palabras Clave: Ganaderías; Tauromaquia; Turismo taurino; México.

Bullfighting tourism as a conservation strategy for a heritage at risk: The case of bullfighting bulls in Tlaxcala, Mexico.

Abstract: In Mexico, the breeding of fighting bulls began in the late 19th century. Tlaxcala is the Mexican state with the largest number of farms. The bullfighting culture is exemplified by the farms, bullfighters, bullfighting schools and bullfights. Currently the cattle-rearers face severe financial problems, due to high production costs, the onerous maintenance of building and the fall in number of events, due to the activism of anti bullfighting groups. This has caused the closure of farms with social, economic, environmental and patrimonial repercussions. This research analyses the perspectives of bullfighting tourism as a heritage resource outside the debate as to its legitimacy, generating income toward its preservation. The methodology considered historical bibliographical review and participant observation with in-depth interviews.

Keywords: Livestock; Bullfighting; Bullfighting tourism; Mexico.

\section{Introducción}

"Una sociedad se define no sólo por lo que crea, sino por lo que se niega a destruir" John Sawhill

En el mundo la actividad turística ha dado muestras evidentes de su capacidad para dinamizar social y económicamente los territorios donde se instala, generando oportunidades de empleo; mejoramiento de infraestructura y de servicios, entre otros beneficios. Así también, es de destacar que al insertarse en un modelo que prioriza el enfoque económico, ha generado asimetrías relacionadas con inequidad social y económica, desequilibrio ambiental, gentrificación de espacios y cambios culturales en comunidades anfitrionas, como puede atestiguarse en la mayoría de los llamados "destinos turísticos exitosos" en

El Colegio de Tlaxcala, A.C (México); E-mail: serafin.rios@coltlax.edu.mx 
México, tanto destinos de playa como Cancún, Quintana Roo; Los Cabos, Baja California; Puerto Vallarta; Jalisco y Acapulco e Ixtapa-Zihuatanejo, en Guerrero; como destinos del interior como San Miguel de Allende, Guanajuato y Valle de Bravo, Estado de México, entre otros.

En el año 2016, según la Secretaría de Turismo federal (SECTUR): "México alcanzó el octavo lugar en la clasificación de llegada de turistas internacionales, al superar a Turquía...Con esto se ha avanzado 7 posiciones en el ranking de turismo internacional... desde el 2013" (SECTUR, 2017, p. 19). Respaldan la relevancia del turismo mexicano, el aporte del 8.7\% al Producto Interno Bruto (PIB); la generación de más de 10 millones de empleos directos e indirectos, aunado a un crecimiento gradual y sostenido que le permitió pasar del lugar 15 en el año 2012 al lugar 8 en 2016, al registrar una afluencia promedio de 35 millones de turistas. Lo anterior, favorecido, según la Secretaría de Turismo Federal “...Por revolucionarios cambios que están ocurriendo en áreas como la industria digital, la inteligencia artificial, la nanotecnología y la biotecnología que seguirán transformando radicalmente la dinámica económica, social, cultural y política, a escala mundial. Al tratarse de una industria global, abierta y altamente competitiva, el turismo será impactado significativamente por estos cambios" (SECTUR, 2017, p. 3). En el contexto internacional la Organización Mundial de Turismo (OMT, 2018), oficializa que México fue el sexto país más visitado durante el 2017 al sumar 39.3 millones de turistas internacionales, lo que representó un incremento del $12 \%$ en relación con el año previo. Contrasta lo anterior con la caída en cuanto a derrama económica, donde México pasó del sitio 14 al 15, siendo un rubro que amerita atención prioritaria por autoridades del sector.

La Organización para la Cooperación y el Desarrollo Económico (OCDE), en su Estudio de Revisión de la Política de Turismo de México, ha señalado que: “...México tendrá que evolucionar a un modelo que permita competir en el cambiante mercado del turismo y apoyar un crecimiento más incluyente y sostenible. Alcanzar los objetivos implicará una mayor vinculación de las entidades gubernamentales, incentivando el desarrollo de empresas pequeñas y microempresas más fragmentadas, desarrollando políticas para apoyar proyectos de menor escala a las pequeñas empresas turísticas. Esto requerirá un enfoque deliberado y centrado en el mercado para el desarrollo de los destinos y la diversificación de productos, con el apoyo del sector privado" (OCDE, 2017, p. 12). En lo enunciado se destaca la importancia de la diversificación de los destinos turísticos, para transitar del modelo mexicano tradicional de turismo de sol y playa, a un modelo diversificado de turismo alternativo que incluya destinos turísticos culturales del interior, con un enfoque responsable, comprometido con la conservación y preservación del patrimonio cultural y natural. El potencial cultural se encuentra evidenciado en su vasta arquitectura civil (centros históricos, ex haciendas, ganaderías, ranchos, etc.), y religiosa (capillas, iglesias, ex conventos y centros religiosos), así como en manifestaciones culturales diversas ( fiestas populares pagano-religiosas, artesanías, gastronomía, charrería; etc.), en tanto su patrimonio natural, se manifiesta en la belleza de sus Áreas Naturales Protegidas (ANP's), bosques, montañas, cascadas, ríos, etc., todo ello constructo de un pasado mesoamericano, colonial, republicano y contemporáneo, que ha configurado un país pleno en contrastes y diversidad cultural. Lamentablemente en México, hasta este momento, no existe una política pública que brinde protección efectiva al patrimonio construido, ya que el Instituto Nacional de Antropología e Historia (INAH) ${ }^{1}$, ha demostrado serias limitaciones para cumplir su función, debido principalmente a insuficiencia presupuestal y atribuciones legales limitadas, lo que ha acotado su capacidad técnica y operativa. Evidencia de la inefectividad institucional referida, es el estudio sobre la hacienda poblana realizado por Yanes y Ríos (2014), donde de 436 haciendas registradas en 1910, para el año 2012, sólo se hallaron en buenas condiciones 108 inmuebles; abonando la investigación sobre haciendas realizada por Ríos (2017) en el estado de Tlaxcala, donde de 145 haciendas y ganaderías registradas por Terán (2002), para 2016 se registraron sólo 65 inmuebles en buen estado. Es decir en los estados de Puebla y Tlaxcala han desaparecido, respectivamente el $75 \%$ y $65 \%$ del inmobiliario histórico representado por ex haciendas, a pesar de contar con un organismo responsable de proteger el patrimonio. Explica lo anterior, que en Latinoamérica, sin ser México la excepción, se padece lo que Romano (2009) en Montenegro (2012), califica como la "despolitización de las políticas públicas", partiendo de que si estas son acciones o propuestas -principalmente gubernamentales- de regulación de numerosos problemas y contradicciones a los que se enfrentan las sociedades contemporáneas, al no cumplir con sus objetivos, concluye que el ciudadano de un actor con derechos que le garantizaban el beneficio de las políticas y servicios, se transforma en consumidor de los nuevos bienes públicos privatizados. Lo anterior se enmarca en la esencia del modelo neoliberal, que cuestiona las funciones del Estado, en aras de posicionar una concepción administrativo-gerencial de la cosa pública.

Por lo anteriormente referido, los propietarios civiles de ganaderías de toros de lidia, deben realizar con recursos propios, actividades de conservación de los inmuebles con las limitaciones que ello 
implica, considerando el elevado costo de las intervenciones necesarias para su rescate, restauración y mantenimiento, teniendo por ello que buscar alternativas de ingresos complementarios, destacando entre estas el turismo.

\section{Contexto de la investigación}

El origen de Tlaxcala, según el Instituto Nacional para el Federalismo y Desarrollo Municipal (INAFED, 2017), se remite al año 1380 d.C., con la llegada de dos grupos étnicos mesoamericanos, primero los Olmecas-Xicalancas, provenientes del Golfo de México, los cuales fueron posteriormente desplazados por los Teochichimecas, llegados del centro del país. El vocablo Tlaxcala, proviene del náhuatl Tlaxcallan que significa "Lugar de Tortillas o Pan de Maíz". La ciudad capital, Tlaxcala, fue fundada en 1525 por el conquistador Hernán Cortes, y años más tarde, debido al rol de aliado estratégico desempeñado por los tlaxcaltecas en la conquista de Tenochtitlán, sede del antiguo imperio azteca, la Corona Española le otorga escudo de armas y la nombra "Muy Noble y Muy Leal Ciudad de Tlaxcala".

El actual estado de Tlaxcala, es la entidad mexicana más pequeña en términos geográficos con una superficie de 4,016 km2, que representa el $0.2 \%$ del territorio nacional; colinda con los estados de Puebla, Estado de México e Hidalgo, y registra una población de 1 millón 273 mil habitantes.

En cuanto a la crianza de toros de lidia, objeto de esta investigación, el estado alberga el mayor número de ganaderías en México. La crianza de toros de lidia, es una actividad distintiva de la cultura tlaxcalteca, que actualmente atraviesa por una grave crisis financiera, debido a los elevados costos de producción, al oneroso mantenimiento de inmuebles, y a la disminución de eventos taurinos con la consecuente baja en la demanda de ganado, su principal fuente de ingresos, situación agudizada principalmente por presiones de grupos anti taurinos. Lo anterior ha provocado según el director del Instituto Tlaxcalteca de Desarrollo Taurino (ITDT) que ganaderías como Coaxamaluca, la Trasquila, José Rodríguez y Felipe González cierren operaciones, con repercusiones: a) económicas, principalmente para los integrantes de la cadena de valor del toro de lidia: ganaderos, toreros, empresarios taurinos, veterinarios, proveedores de insumos y materiales entre otros, aunado a la pérdida de empleos de residentes de comunidades aledañas que laboran en las ganaderías, prestando servicios relacionados con mantenimiento de instalaciones (albañiles y jornaleros), cuidado del campo y del ganado (peones, vaqueros y caporales), servicios en cocina y de intendencia; $b$ ) sociales, en el entorno de las ganaderías se localizan comunidades, la mayoría originadas por el reparto de tierras de la otrora hacienda ganadera, por ello los vínculos de relación actual comunidades-ganaderías son históricos y de reciprocidad, aunque no exentos de conflictos. Cabe destacar también, la presencia que en la mayoría de fiestas patronales, aún en las más modestas, tiene la cultura taurina, a través de las corridas de toros para regocijo de grandes segmentos de la población y, c) repercusiones ambientales, los campos de crianza, son ecosistemas bien conservados, al tener como guardián al toro de lidia, labor complementada por la prohibición en esos espacios del tránsito y de la cacería. Por lo anterior, la eventual desaparición de las ganaderías de toros de lidia, aún con sus claroscuros y la polarización social que generan, representaría para segmentos importantes de la población tlaxcalteca una pérdida invaluable en términos no solo económicos, sociales, ambientales, sino también patrimoniales.

Este articulo tiene como objetivo analizar la pertinencia de una propuesta del turismo taurino que permita, tanto al turista nacional como internacional, acceder al conocimiento y comprensión de la cultura taurina tlaxcalteca como un proceso, que va más allá de su evento más polémico: la fiesta brava; al tiempo de generar ingresos que coadyuven a la conservación de las ganaderías.

\section{Antecedentes del toro de lidia}

Según la Asociación Nacional de Criadores de Toros de Lidia (ANCTL) en García (2017) los orígenes del toro bravo, datan de tiempos remotos, como lo atestigua el hallazgo del fósil más antiguo de una especie provista de cuernos, que se encontró en el Plioceno, mucho antes de la existencia del hombre. Posteriormente en la era Cuaternaria, se encontró el Bos nomadicus, un ejemplar de menor tamaño, pero de cornamenta más desarrollada. Así, tenemos un proceso evolutivo de largo recorrido, que abarca desde el "Bos taurus celticus" representado en las pinturas rupestres, pasando por los bóvidos de los juegos ancestrales de carácter religioso de las antiguas fiestas taurinas populares, hasta llegar a las modernas plazas de toros. 
Desde tiempos antiguos, según Chávez: “...Los toros bravos han sido parte de un culto ancestral, relacionado con un Dios totémico, los antiguos griegos, árabes, judíos, cartagineses, góticos, romanos, cristianos y gitanos, lo colocaron en un sitio de honor, y como una herencia milenaria, incluso transcultural, se tuvo la dicha de seguir su trayectoria mediterránea y recibirlo en su ruta trasatlántica" (Chávez, 2014).

En cuanto al toro de lidia, según García (2017), ya como una actividad especializada que buscaba resaltar, atributos relacionados con bravura, estampa y nobleza al embestir; tenemos que los primeros sitios de crianza se localizaron en la Península Ibérica, el toro más fiero era habitual que proviniera de regiones peninsulares, donde se localizaban enormes dehesas o espacios de crianza, destacando las regiones de Castilla la Vieja, que comprendía la zona de Raso del Portillo en Valladolid y Peñaranda de Bracamonte en Salamanca; Castilla la Nueva, con las zonas de Ojos del Guadiana en la Provincia de Ciudad Real y de Alcalá de Henares en Madrid, reses que con posterioridad pasarían a la zona de Colmenar Viejo, donde la influencia de ríos Tajo y Guadiana serían de suma importancia en su crianza y evolución; en el Norte de España, sobresalen la región Navarra y Aragonesa, en torno al río Ebro y la zona de Tudela, y finalmente la región de Andalucía, en la zona marismeña del Guadalquivir, concretamente Utrera, sede de las principales vacadas andaluzas, que terminarían siendo predominantes de una manera casi absoluta, tras el nacimiento de la lidia a pie.

Respecto al inicio de la tauromaquia en La Nueva España, tenemos, que existen varias versiones acerca del inicio de esta práctica, a decir de Nicolás Rencel (1946) en su obra "Historia del Toreo en México, 1529-1821", la primera corrida en el entonces territorio de Anáhuac, se efectuó el 13 de agosto de 1529 en la Plaza Mayor de México; en tanto, el investigador José de Jesús Núñez, indica que la primera corrida de toros fue el 24 de junio en el marco de las fiestas en honor a San Juan Bautista. Para fines de esta investigación, se asume la versión de Rencel, por considerarla con mayores fundamentos, y que refiere, según Rodríguez en una de sus crónicas: "El miércoles 11 de agosto de 1529 un grupo de autoridades de alto rango, en solemne reunión, acordó que anual y en honor del señor San Hipólito, en cuyo día se ganó la Ciudad de México, se corrieran siete toros y dos de ellos pasaron por el amor de Dios a los hospitales y asilos. Desde 1535 no hubo llegada de virrey nuevo sin varios días de corridas. Toros embolados y las cucañas divertían mucho a todo el mundo. Los alcaldes mandaban teñir de rojo las mantas para las fiestas. Unos capeaban y otros rejoneaban, en su mayoría querían participar" (Rodríguez, 2002).

Es importante referir la implantación del sistema de haciendas en la Nueva España como antecedente del nacimiento de la fiesta brava, debido que las haciendas al erigirse en unidades productivas, generalmente autosuficientes, albergaban diversas actividades productivas, principalmente agrícolas y ganaderas, produciendo en estas últimas, tanto ganado doméstico para consumo, como toros bravos para lidiar con fines recreativos. Cabe resaltar, con fines de contextualización que en cuanto al origen de la hacienda mexicana esta se remonta a "...la hacienda andaluza que se asienta, como modelo, a partir de la ocupación del Valle del Guadalquivir por los castellanos, entre los siglos XIV y XVI, influida por la adopción de la idea social de la nostalgia por el campo, propia de la transición al Renacimiento" (Torices y Zurita, 2003: 58). A partir del siglo XVII, la hacienda constituyó en la Nueva España una unidad productiva con una organización compleja, con características estructurales muy concretas, mismas que explicaban su florecimiento, siendo estas: “...a) dominio sobre los recursos naturales de una zona (tierra y agua); b) dominio sobre la fuerza de trabajo; y c) dominio sobre los mercados regionales y locales" (Nickel, 1978: 10).

La segunda mitad del siglo XIX, marca el inicio de la crianza de toros de lidia en México, emergiendo las ganaderías como unidades especializadas, orientadas a la selección de particularidades sobresalientes en sus ejemplares, tales como: tamaño, peso, estatura, conformación de tronco, extremidades, cabeza, cuello y cornamenta, entre otras. La primera ganadería de toros de lidia formalmente establecida y especializada en la crianza de toro de lidia en México, a decir de Hernández (2013:30), fue la ganadería de "Atenco", ubicada en el Estado de México, precursora de una actividad que según Camacho (2012), recupera el conocimiento estético y científico del toro de lidia, desencadenando en México la emergencia de diversas manifestaciones artísticas relacionadas con la fiesta brava principalmente (pintura, escultura, literatura, música entre otras).

La localización geográfica, el clima y el auge del sistema de haciendas en el centro México, fueron factores determinantes para que el estado de Tlaxcala, se erigiese en lugar idóneo para la cría del ganado de lidia, siendo en el año de 1874 cuando se funda la primera ganadería de toros de lidia: San Mateo Huixcolotepec, mejor conocida como Piedras Negras, localizada en el municipio de Tetla de la Solidaridad, siendo considerada una de las ganaderías madre de México; esta fue secundada por San José Tepeyahualco, ya desaparecida. Posteriormente, en la última década del siglo XIX, surgen las 
ganaderías de San Lorenzo Soltepec, La Trasquila, San José Atlanga, y San José la Laguna. A partir de esta fecha, los ganaderos tlaxcaltecas, empezaron a manejar el ganado de una manera cuidadosa, resaltando particularidades sobresalientes, teniendo como base un sistema de selección, tanto de caracteres externos como de comportamiento, con el propósito de conseguir animales de buena presencia, bravos y poderosos, independientemente del costo que implicara su crianza. Se empieza a utilizar con fines de control, marcas y señales del ganado, hasta la aparición de la divisa ${ }^{2}$, como signo distintivo de cada ganadería. Es importante no soslayar lo planteado por Ramírez (1990), en Ríos (2017), quién menciona que ante el declive de la actividad pulquera y cerealera en las haciendas tlaxcaltecas a principios del siglo XX, surge en Tlaxcala, como alternativa, la crianza de ganado mayor como actividad emergente, posicionándose en este nuevo giro productivo, la crianza del toro de lidia. Conviene señalar que este hecho resultaría un salvoconducto contra la expropiación de las tierras de las haciendas iniciada a fines de la década de 1930, debido a que la Reforma Agraria implementada por el Presidente Lázaro Cárdenas ${ }^{3}$ protegió a las haciendas ganaderas, mediante la creación de la figura jurídica de los certificados de inafectabilidad ganadera. Los primeros certificados fueron otorgados en el periodo 1938-1944, con una vigencia de 25 años; al término de este tiempo, las haciendas dejaban de contar con esta protección legal, no obstante, para proteger íntegramente su propiedad ante eventuales expropiaciones, los propietarios de las haciendas iniciaban la gestión de certificados de inafectabilidad, ya no ganaderos, sino agrícolas, figura complementaria surgida posteriormente. Así los hacendados tlaxcaltecas, mediante estas figuras legales, lograron su propósito de transitar el reparto agrario con expropiaciones menores. Entre las ganaderías tlaxcaltecas beneficiarias de los mencionados certificados figuraron: San Francisco Tecoac; San Martín Notario y San Diego Meca; San Diego Xalpatlahuaya; Zoquiapan; Atlangatepec; Piedras Negras y La Laguna; San Miguel Mimiahuapan, Coaxamalucan; Guadalupe; San Lorenzo Soltepec; Mazaquiahuac; El Rosario; Zotoluca o Rancho Seco, y San Buenaventura. Para el año 1940 se localizaban en Tlaxcala 16 ganaderías, ocupando una superficie promedio de 22,639 hectáreas, las ganaderías con mayor superficie eran Piedras Negras y La Laguna, con 5,000 hectáreas. La superficie del territorio tlaxcalteca ocupado por haciendas y/o ganaderías, ascendía al 6.7 \% de la superficie estatal.

\section{Cuadro 1: Principales diferencias entre haciendas y ganaderías mexicanas}

\begin{tabular}{|c|c|}
\hline Haciendas & Ganaderías \\
\hline $\begin{array}{l}\text { - Surge del modelo andaluz de hacienda, y funge } \\
\text { como instrumento de control económico, social, } \\
\text { político y territorial. }\end{array}$ & $\begin{array}{l}\text { - La crianza de toros de lidia formaba parte de la } \\
\text { estructura productiva de la hacienda. }\end{array}$ \\
\hline $\begin{array}{l}\text { - Las haciendas surgen en el siglo XVI, y se } \\
\text { consolidan a finales del siglo XIX. }\end{array}$ & $\begin{array}{l}\text { - Las ganaderías emergen como unidades } \\
\text { productivas especializadas a mediados del siglo } \\
\text { XIX }\end{array}$ \\
\hline $\begin{array}{l}\text { - Se sustentó en tres figuras jurídicas: merced de } \\
\text { tierras, encomiendas y compra-venta de tierras. }\end{array}$ & $\begin{array}{l}\text { - Las ganaderías de toros de lidia, formaban parte } \\
\text { de la cultura productiva y recreativa peninsular }\end{array}$ \\
\hline $\begin{array}{l}\text { - El reparto de tierras de las haciendas iniciado en } \\
\text { 1912, generó la propiedad ejidal, formalizada en } \\
1934\end{array}$ & $\begin{array}{l}\text { - La figura de certificados de inafectabilidad } \\
\text { ganadera, favoreció la conversión de haciendas en } \\
\text { ganaderías. }\end{array}$ \\
\hline $\begin{array}{l}\text { - El concepto de hacienda y por tanto de } \\
\text { hacendado, no existe más al perder las } \\
\text { características que le dieron origen. }\end{array}$ & $\begin{array}{l}\text { - La figura de la ganadería y del ganadero, a pesar } \\
\text { de la crisis, son conceptos aún vigentes. }\end{array}$ \\
\hline
\end{tabular}

Fuente: Elaboración propia

Actualmente Tlaxcala es el estado con más ganaderías de toros de lidia en México, con un total de 33, seguido por los estados de Guanajuato y Jalisco con 32 y 31, respectivamente. Así, la cultura taurina se ha convertido en un patrimonio cultural que identifica al estado, siendo la tauromaquia o fiesta brava, la más conocida y polémica de sus manifestaciones, la de mayor arraigo popular, al formar parte importante de la mayoría de las fiestas patronales, donde en plazas fijas o móviles, desde las monumentales hasta las más modestas, las corridas de toros y/o novilladas, forman parte 
del espíritu festivo del pueblo tlaxcalteca. Destacan, entre otras, las ferias de los municipios de Huamantla, con su ya famosa Huamantlada y corrida de las Luces; Tlaxcala capital; Apizaco; Tlaxco; Tetla de la Solidaridad; Santa Ana Chiautempan, y Altzayanca. Según Camacho: "La fiesta de los toros en Tlaxcala, junto con otras costumbres, es producto de la mezcla cultural de dos sociedades, la española y la mexicana, identificadas por el gozo de las fiestas y el solemne respeto a las tradiciones" (Camacho, 2012:17).

Para esta investigación la cultura taurina será concebida, parafraseando a Tylor (1871) en Kahn (1975) como aquel complejo de conocimientos, creencias, hábitos, moral, costumbres y saberes relacionados con la crianza del toro bravo, que algunos segmentos de la sociedad conocen, valoran e identifican como propios. En cuanto al turismo taurino, este será entendido como la actividad, donde el principal motivo de visita está dado por el interés del turista en conocer la cultura taurina, conformada por la historia, la arquitectura, el proceso de crianza (manejo, alimentación, sanidad y reproducción), la gastronomía, la música, los rituales, mitos y leyendas, la cadena de valor del toro de lidia, entre otros aspectos. La oferta de turismo taurino propuesta, pretende proporcionar información y elementos al visitante, que le permitan conocer y comprender la cultura taurina tlaxcalteca, como un proceso, que va más allá de la fiesta brava o tauromaquia. Lo anterior permitiría al tiempo de revalorar una manifestación cultural relevante, generar recursos que coadyuven a la preservación de las ganaderías.

\section{Metodología}

La propuesta metodológica de esta investigación fue de corte cualitativo e incluyó: 1) revisión documental de antecedentes histórico-culturales; 2 ) análisis de la oferta turística nacional y estatal; 3) estudio de caso de cuatro ganaderías tlaxcaltecas de toros de lidia: Piedras Negras (Municipio de Tetla de la Solidaridad); San Pedro Tenexac Municipio de Terrenate); Rancho Seco (Municipio de Tlaxco) y Coyotepec (Municipio de Cuapiaxtla), las cuales fueron seleccionadas considerando criterios relacionados con estado físico, funcionalidad del inmueble; antigüedad e historia; giro productivo; perfil del propietario (heredero o inversionista,); oferta actual de servicios turísticos, recreativos y/o sociales; accesibilidad; disposición para participar e interés por invertir, y 3) observación participante, con visitas diversas a las ganaderías seleccionadas y la realización de entrevistas abiertas con actores clave: ganaderos, funcionarios públicos, turoperadores, cronistas municipales y guías de turistas.

\section{Desarrollo del tema}

Los principales atractivos turísticos culturales del estado, se fundamentan en su riqueza patrimonial tangible derivada tanto de la cultura mesoamericana, evidenciada en 7 sitios arqueológicos, como la cultura colonial, representada por la arquitectura civil de 65 ex haciendas activas y 33 ganaderías de toros de lidia, aunadas a la arquitectura religiosa, conformada por ex conventos franciscanos, iglesias, capillas y santuarios donde destacan el de San Miguel del Milagro y el de Nuestra Señora de Ocotlán. Suman a lo anterior diversas manifestaciones culturales propias del mestizaje: artesanías, gastronomía, charrería, tauromaquia y más de 200 fiestas populares cívico religiosas y su famoso carnaval. En cuanto a la relevancia de la cultura taurina en Tlaxcala, da cuenta de ello, los 350 $\mathrm{km}_{2}(8.7 \%)$ del territorio tlaxcalteca dedicado a la crianza del ganado bravo; la localización de tres escuelas taurinas; dos museos taurinos y catorce plazas de toros, entre las que destaca en la Ciudad de Tlaxcala uno de los cosos taurinos más antiguos y hermosos de México: La Plaza de Toros Jorge Aguilar "El Ranchero", considerada monumento Histórico del Siglo XIX. Aparejado al auge de las ganaderías, surgieron matadores tlaxcaltecas importantes, destacando Antonio Ortega "El Marinero"; Fernando de los Reyes "El Callao"; Jorge Aguilar "El Ranchero"; y Rodolfo Rodríguez "El Pana", y la tradición se mantiene hasta nuestros días con matadores como Rafael Ortega "Señor de los 3 Tercios"; Uriel Moreno "El Zapata"; José Luis Angelino y Sergio Flores, entre otros. Así, la tauromaquia o corrida de toros, es de la cultura taurina, la manifestación con mayor arraigo popular. En cuanto a la localización geográfica de las ganaderías de toros de lidia en Tlaxcala, éstas se ubican en 12 de los 60 municipios del estado: Atlangatepec (9); Tetla de la Solidaridad (6) y Tlaxco (6); Huamantla (3); Terrenate (2); y con una ganadería están los municipios de Españita, Apizaco, Xaltocan, Xalóstoc, Hueyotlipan. Lázaro Cárdenas y Cuapiaxtla (ver Cuadro 2). 


\section{Cuadro 2: Ganaderías de toros de lidia del Estado de Tlaxcala}

\begin{tabular}{|c|c|}
\hline Ganadería & Municipio \\
\hline 1. Atlanga & Atlangatepec \\
\hline 2. Coaxamaluca & Tetla de la Solidaridad \\
\hline 3. Brito & Huamantla \\
\hline 4. Coyotepec & Cuapiaxtla \\
\hline 5. Cuatro Caminos & Tlaxco \\
\hline 6. Darío González & Tetla de la Solidaridad \\
\hline 7. De Haro & Terrenate \\
\hline 8. Doña Altagracia & Xaltocan \\
\hline 9. El Cuate González & Tlaxco \\
\hline 10. El Grullo & Atlangatepec \\
\hline 11. Felipe González & Tetla de la Solidaridad \\
\hline 12. García Méndez & Apizaco \\
\hline 13. José María Arturo Huerta & Tlaxco \\
\hline 14. José María González & Atlangatepec \\
\hline 15. José Rodríguez & Atlangatepec \\
\hline 16. Juan Huerta & Españita \\
\hline 17. La Gasca & Atlangatepec \\
\hline 18. La Soledad & Tetla de la Solidaridad \\
\hline 19. La Laguna & Lázaro Cárdenas \\
\hline 20. La Trasquila & Atlangatepec \\
\hline 21. Los González & Atlangatepec \\
\hline 22. Montecristo & Hueyotlipan \\
\hline 23. Olivares & Atlangatepec \\
\hline 24. Piedras Negras & Tetla de la Solidaridad \\
\hline 25. Rancho Seco & Tlaxco \\
\hline 26. San Cristóbal de Padua & Huamantla \\
\hline 27. San Antonio Tepetzala & Atlangatepec \\
\hline 28. San Cristóbal la Trampa & Huamantla \\
\hline 29. San Lorenzo Soltepec & Tlaxco \\
\hline 30. San Pedro Tepetzala & Tetla de la Solidaridad \\
\hline 31. San Pedro Tenexac & Terrenate \\
\hline 32. Toros de Santo Tomás & Tlaxco \\
\hline 33. Zotoluca & Xalostoc \\
\hline
\end{tabular}

Fuente: Instituto de Desarrollo Taurino de Tlaxcala (IDTT, 2018)

La trascendencia de la cultura taurina en Tlaxcala, desde el punto de vista gubernamental, se hace patente en tres eventos oficiales relevantes: 1. El reconocimiento otorgado en 1986 a la ganadería de San Pedro Tenexac (municipio de Terrenate), la cual por Decreto Presidencial, a través del Instituto Nacional de Antropología e Historia (INAH), fue reconocida como Monumento Histórico de la Nación; 2. El Decreto de Declaratoria de la Fiesta de los toros como Patrimonio Cultural Inmaterial del Estado 
de Tlaxcala, emitido por el H. Congreso del Estado, aprobado el 26 de abril del 2012, y 3. La creación del Instituto de Desarrollo taurino del Estado de Tlaxcala (IDTT) en septiembre del 2003.

Es conveniente mencionar que un segmento importante de la población en Tlaxcala se manifiesta abiertamente en contra de la fiesta brava, pero más allá de filias y fobias, ésta debe entenderse en el marco de un contexto mayor del que forma parte: La cultura taurina, la cual genera efectos positivos en términos: a) culturales, ya que permite la conservación de un patrimonio arquitectónico y mobiliario relevante (algunas ganaderías albergan murales, pinturas, documentos y muebles de alto valor histórico y material); b) económicos, el efecto dinamizador de la economía que caracteriza a la actividad turística, se refleja en la cadena de valor en torno a la crianza del toro bravo, donde concurren: ganadero-torero-empresario-aficionado-turista y comunidades, en estas últimas, las ganaderías ofrecen alternativas de ingresos a los habitantes, mediante la prestación de servicios y/o suministro de productos locales, tanto a ganaderos como a visitantes; c) sociales, prevalecen relaciones históricas de beneficio, generalmente desigual, entre ganadería y comunidades, recordando que el reparto de tierras de las haciendas durante la reforma agraria mexicana, dio origen a comunidades; $d$ ) ambientales, en Tlaxcala las ganaderías albergan en los campos de crianza ecosistemas bien conservados, que tienen como garante al toro bravo, y e) turísticos, Tlaxcala se ha unido exitosamente a estados como Querétaro, San Luis Potosí, Guanajuato, Estado de México y Jalisco, donde el turismo taurino, ha venido a diversificar y enriquecer significativamente, aún con sus limitaciones actuales, la oferta turística actual.

En cuanto a la actividad turística en Tlaxcala, esta ha tenido un importante auge en los últimos cinco años, ante el surgimiento de productos emergentes, tales como “... El Santuario de las Luciérnagas y la declaratoria de Tlaxco como "Pueblo Mágico" ", lo cual ha favorecido su crecimiento en los últimos años en un 13 \%" según la Secretaria de Turismo y Desarrollo Económico del Estado (SETYDE, 2015). Los segmentos de turismo que caracterizan al estado son: Turismo rural, de naturaleza y principalmente el turismo cultural, segmento donde el turismo taurino empieza a destacar, debido a la fama de "estado taurino" que tiene Tlaxcala a nivel nacional.

En relación a la oferta turística estatal, la Secretaria de Turismo del Estado de Tlaxcala (SECTURE, 2017), ha determinado para el estado 6 rutas turísticas: 1) Tlaxcala, Corazón de la historia "Joya histórica por descubrir", tiene como sede la Ciudad de Tlaxcala con una oferta cultural vasta; 2) Arqueología, herencia ancestral "Vestigios del pasado en un viaje por el presente", gira en torno a los primeros grupos que habitaron lo que hoy es el estado de Tlaxcala; 3) El pulque y la luciérnaga "Sabor y magia, regalo de la naturaleza", tiene como eje el proceso de producción del pulque; 4) El Santuario de las luciérnagas ubicado en el espolón de la Sierra Nevada, considera el avistamiento estacional de luciérnagas en los meses de julio y agosto; 5) Haciendas y ganaderías "Con un pasado tan vivo que lo puedes sentir", evidencia la riqueza del campo tlaxcalteca durante la época de la Colonia y, 6) Color y tradición de Tlaxcala "Tradiciones que viven el presente, con rasgos del pasado", en esta ruta conocerás los dos Pueblos Mágicos de Tlaxcala.

Las propuestas turísticas oficiales, relacionadas con turismo taurino, a pesar de la relevancia de la cultura taurina descrita, la conforman dos rutas: 1. Haciendas y ganaderías, y 2. Puyazo taurino del programa de turismo experiencial Tonali (financiado por el gobierno federal), ambas propuestas son comunes, carentes de creatividad y no reflejan la relevancia y riqueza que la cultura taurina tlaxcalteca encierra.

Es importante aclarar que en México el modelo de turismo de haciendas tiene como antecedente, según Fierro (2015) el proyecto de rescate de las ex-haciendas henequeneras de los estados de Yucatán y Campeche a finales de la década de 1990. Entre sus principales características actuales se encuentran: a) orientación hacia turistas con alto poder adquisitivo; b) oferta de alojamiento, restauración, eventos sociales y actividades recreativas y lúdicas de gran lujo; y c) se encuentran incorporadas al Consejo Nacional Empresarial Turístico (CNET), órgano que agrupa a las empresas turísticas más solventes de México. Los principales referentes de este tipo de turismo son: Grupo Plan que integra a cinco ex-haciendas henequeneras, entre estas Temozón (Yucatán) y Uayamon (Campeche); la Asociación de Haciendas y Casonas de Jalisco, organización que agrupa 30 hoteles de lujo en el estado de Jalisco, entre estos las haciendas Sepúlveda y El Carmen, y la Federación de Haciendas de México, asociación civil que representa a 13 ex-haciendas, localizadas en varios estados del país, entre las que destacan: Ex hacienda Cocoyoc (Morelos) y San Andrés la Retana (Estado de México). El modelo referido se halla en sintonía con el Turismo de Intereses Especiales (TIE) el cual, según Espinoza et al (2014), se fundamenta en viajes individualizados, no comercializados en forma masiva, sino diseñados a la medida de cada turista, es decir personalizados.

En cuanto a esta investigación, parte de las premisas del turismo alternativo concebido según Bringas \& González (2003), como un factor para el desarrollo local sostenible, es decir como un elemento que dinamiza la economía del lugar con fuentes alternativas de ingresos sin tener que destruir sus recursos 
para poder subsistir, buscando la apertura democrática del sector. Lo anterior ante el modelo de turismo de haciendas predominante, abre oportunidades para un tipo de turismo rural de haciendas y ganaderías diversificado y creativo, que configure una oferta, tanto para turistas que buscan exclusividad, como para la población abierta con precios accesibles. La propuesta de servicios a ofertar se conforma por recorridos temáticos, alojamiento, servicio de restaurante y actividades interactivas. Actualmente la visita turística a las haciendas y ganaderías de Tlaxcala, se gestiona a través de turoperadoras locales como Paseos de San Francisco y México Viejo Tours, esta última oferta una visita a las ganaderías de San Pedro y la Laguna (donde por cierto ya no se crían toros) que incluye recorridos guiados, con transporte y una comida, a un costo de $\$ 950.00$ por adulto y de $\$ 550.00$ para niños. Por su parte, las ganaderías como Piedras Negras, San Pedro Tenexac, Rancho Seco, Coyotepec, objeto de esta investigación, ofertan servicios turísticos de manera esporádica, relacionados con visitas guiadas, recorridos a campos de crianza y comida, ya sea en paquete o por actividad, con costos que oscilan entre $\$ 250.00$ y $1,050.00$ por persona, dependiendo de los servicios solicitados, edad, número de visitantes y tipo de ganadería.

Para lograr el objetivo de esta investigación se propone una propuesta de visita turística que evidencie creativamente la riqueza de la cultura taurina tlaxcalteca, con el propósito de lograr un conocimiento amplio de la misma. La propuesta referida de actividades deberá alinear objetivos, servicios, condiciones de visita, recursos, personal capacitado y tiempos de estancia.

\section{Hallazgos de investigación}

Esta investigación, realiza un estudio de caso de cuatro de las ganaderías más emblemáticas del estado: Piedras Negras o San Mateo Huixcolotepec, la cual se localiza en el municipio de Tetla de la Solidaridad al Centro-Norte del estado, considerada la ganadería madre en México; San Pedro Tenexac, hacienda y ganadería que se erige en el municipio de Terrenate al Oriente del estado, obtuvo un reconocimiento en 1986, por Decreto Presidencial, a través del Instituto Nacional de Antropología e Historia (INAH), fue reconocida como Monumento Histórico de la Nación; Rancho Seco, radicada en el municipio de Tlaxco al Norte del estado, es una de las ganaderías más dinámicas, pionera en el campo turístico, y Coyotepec, ubicada en el municipio de Cuapiaxtla al Oriente del estado, se ha posicionado como una de las ganaderías más activas en términos taurinos con venta de ejemplares dentro y fuera del estado. Las ganaderías fueron seleccionadas, a partir de criterios relacionados con estado físico del inmueble; antigüedad; giro productivo; perfil del propietario; prestación de servicios turísticos; accesibilidad y disponibilidad para invertir.

\section{Cuadro 3: Características de ganaderías seleccionadas}

\begin{tabular}{|c|c|c|c|c|c|}
\hline Ganadería & Municipio & $\begin{array}{c}\text { Perfil de } \\
\text { Propietario }\end{array}$ & Turismo & \multicolumn{2}{|c|}{ Servicios } \\
\hline Piedras Negras & Tetla & Heredero & Premiun & Turismo & Eventos sociales \\
\hline $\begin{array}{c}\text { San Pedro } \\
\text { Tenexac }\end{array}$ & Terrenate & Heredero & Premiun & Turismo & Eventos sociales \\
\hline Rancho Seco & Tlaxco & Inversionista & Social & Turismo & Eventos sociales \\
\hline Coyotepec & Cuapiaxtla & Inversionista & Social & Turismo & Eventos sociales \\
\hline
\end{tabular}

Fuente: Elaboración propia

La metodología aplicada, permitió confirmar el insuficiente conocimiento que los actores turísticos (funcionarios, turoperadores y guías de turistas), así como segmentos importantes de la sociedad tlaxcalteca, tienen acerca de la cultura taurina, al focalizar la atención en la fiesta brava, su evento más polémico, lo que impide el acercamiento de posturas y una eventual comprensión de la actitud y pensamiento del otro.

Los hallazgos descritos fundamentan la pertinencia de una propuesta de turismo taurino, que posibilite, el conocimiento y valoración de la cultura taurina tlaxcalteca, para lograrlo es necesario el diseño de una oferta turística atractiva, que evidencie creativa e integralmente: a) la historia y origen del toro bravo ; b) el hábitus del ganadero y de los toreros; c) la arquitectura de la ganadería con recorridos guiados a espacios habitacionales (casa del ganadero) y espacios productivos (corrales, campos de crianza, cortijo, silos, etc.); d) el proceso del manejo (crianza, reproducción, selección y sanidad); e) la alimentación (campos de pastoreo, capacidad de carga, dietas, etc.); f) actividades interactivas como la 
tienta de vaquillas; marcado de ganado (herraje), cabalgatas, lunadas, tertulias temáticas, entre otras; e) la gastronomía, bebidas (pulque, mezcal y tequila) y música ; f) rituales, mitos y leyendas taurinas; g) la cadena de valor del toro de lidia (producción, comercialización y eventos taurinos) que incluye a ganaderos, toreros, empresarios, afición, turoperadores, turistas y comunidades y, h) descripción de los efectos sociales, económicos y ambientales de la crianza del toro bravo y del turismo taurino. La visita deberá contar con un equipo de especialistas en la cultura taurina, entre ellos un guía especializado, el ganadero o administrador, el caporal, peones, toreros retirados o en activo.

En cuanto a los segmentos de turismo a los cuales deberá orientarse la oferta de turismo taurino, determinados a partir de la investigación son: 1.Turismo premiun, dirigido a visitantes con alto poder adquisitivo, ofertado por ganaderías donde el propietario es heredero, y manifiesta inclinación por recibir a visitantes conocedores de la cultura taurina y/o con suficiente solvencia económica para cubrir servicios con altos estándares de calidad, siendo el caso de las ganaderías Piedras Negras y San Pedro Tenexac, y, 2. Turismo social, orientado a turistas con poder adquisitivo que va de medio a alto, con una oferta flexible, en términos generales el propietario tiene un enfoque pragmático de negocios, ejemplifican lo anterior los propietarios de las ganaderías Rancho Seco (Tlaxco) y Coyotepec (Cuapiaxtla). Para propósitos de esta investigación, es importante mencionar que en las entrevistas con el director del Instituto Tlaxcalteca de Desarrollo Taurino (ITDT), manifestó que la mayoría de los ganaderos en el estado, se muestran interesados en incorporarse a la actividad turística, situación que permitirá bajo el concepto planteado, el conocimiento y valoración de la cultura taurina como un proceso que trasciende a la fiesta brava, al tiempo de convertirse en una alternativa generadora de recursos necesarios para la preservación de las ganaderías tlaxcaltecas, patrimonio hoy en riesgo.

\section{Conclusiones}

El momento turístico por el que atraviesa el turismo mexicano, avizora un futuro promisorio para el turismo tlaxcalteca, y por tanto fundamenta la pertinencia de la propuesta de turismo taurino orientada a promover en el turista local, nacional e internacional el conocimiento y comprensión de la cultura taurina, teniendo como eje la vasta cultura taurina que caracteriza al estado de Tlaxcala evidenciada en sus 33 ganaderías; lo anterior complementado por un potencial turístico cultural, donde destacan los Pueblos Mágicos de Huamantla y Tlaxco; 85 ex haciendas activas; cuatro zonas arqueológicas; Centros Históricos relevantes; recursos naturales importantes, tales como Área Natural Protegida la Malinche (ANP-Malinche) y bosques del espolón de la Sierra Nevada; el atractivo estacional (Julio-Agosto) más importante denominado Santuario de las luciérnagas y las diversas fiestas que caracterizan al estado, donde las corridas de toros son parte del espíritu festivo popular. Adicionalmente se cuenta con una cercanía estratégica con la Ciudad de México, capital del país, con un mercado potencial de 20 millones habitantes, localizado a 90 minutos por vía terrestre con excelente conectividad. Partiendo del entorno favorable descrito, para lograr que la oferta de turismo taurino en Tlaxcala logre posicionarse y generar recursos necesarios para la conservación de los inmuebles ganaderos y de la cultura taurina en general, deberán participar tanto en su diseño como en su operación personal especializado que incluya: historiadores, especialistas en turismo cultural, gestores turísticos, ganaderos, toreros retirados y en activo, novilleros y guías especializados. Fundamental para el éxito de la propuesta será la coordinación estatal entre los diversos actores del turismo, tanto gubernamentales (comunitario, municipal y estatal); empresariales(prestadores de servicios de alojamiento, restauración, guías de turistas y turoperadores, entre otros) y sociales (organizaciones protectoras de animales, ambientalistas, etc.), para emprender una cruzada conjunta en defensa de un patrimonio, que más allá de filias y fobias, representa un pasado, sin el cual no se puede explicar el presente de la sociedad tlaxcalteca.

\section{Bibliografía}

Bringas, R. N. y González, A. J.I. 2003. "El turismo alternativo: una opción para el desarrollo local en dos comunidades indígenas de Baja California”. En Economía, Sociedad y Territorio, vol. IV, núm. $15,2004,551-558$

Camacho, M. 2012. Exposición de motivos para el Decreto de Declaratoria de la Fiesta de los toros como Patrimonio cultural inmaterial del Estado de Tlaxcala, emitido por el H. Congreso del Estado de Tlaxcala, aprobado el 26 de abril del 2012.

Chávez, M. C. 2014. Revista Matador, 6 (6), edición de colección. 
Espinoza, A., Llancaman L., Sandoval, H. 2014. Turismo de intereses especiales y parques nacionales. Compatibilidad entre turismo de intereses especiales y gestión de parques nacionales, estudios de perspectiva turística, Vol. 33, № 1 , Ciudad Autónoma de Buenos Aires

Fierro, I.G. 2015. "Turismo de hacienda e intervención comunitaria en el contexto rural yucateco. El caso de la Fundación Haciendas del Mundo Maya”, Desacatos, n 52, CIESAS, México.

Hernández, C. 2013. La legendaria hacienda de Piedras Negras su gente y sus toros, Impretlax, México.

Instituto Nacional para el Federalismo y el Desarrollo Municipal (INAFED) 2017. Enciclopedia de los municipios y delegaciones de México-Tlaxcala

Kahn, J.S. (Compilador) 1975. El concepto de cultura: Textos Fundamentales (escritos de Tylor (1871), Kroeber (1917), Malinowski (1931), White (1959), y Goodenough (1971), Editorial Anagrama, Barcelona: Anagrama.

Montenegro, J. 2012. "Los conflictos del desarrollo en la producción del espacio brasileño: El caso del desarrollo territorial rural y sus condiciones de posibilidad”, Revista Regiones y Desarrollo Sustentable, $\mathrm{N}^{\circ} 21$ y 22 , El Colegio de Tlaxcala, A.C., México

Nickel, H. 1978. Morfología social de la hacienda mexicana, Ed. Franz Steiner, Weisbaden.

Organización para la Cooperación Económica y el Desarrollo (OCDE). 2017. Estudio de la Política Turística en México. Resumen ejecutivo, evaluación y recomendaciones. Recuperado:https://wwwl. oecd.org/industry.tourism/MEXICO\%20TOURISM\%20POLICE\%20REVIEW_EXEC\%20SUMM\%20 ASSESSMENT\%20AND\%20RECOMENDATIONS.ESP.pdf, consultado 20 de diciembre del 2018.

Organización Internacional de Turismo (OMT) 2018. Panorama Mundial OMT del turismo internacional.

Proyecto de Decreto mediante el cual se declara a la Fiesta de toros patrimonio cultural inmaterial del Estado de Tlaxcala, 2012.

Rencel, Nicolás 1946. Historia del toreo en México 1529-1821. Época Colonial, consultado en Dirección General de Bibliotecas, dgb.conaculta.gob.mx/coleccin_sep/libro_pdf/13000000596.

Ríos, S. 2017. Dinámica socioeconómica de la hacienda tlaxcalteca: Situación actual y perspectivas, Secretaría de Cultura, Instituto Tlaxcalteca de Cultura y El Colegio de Tlaxcala, AC

Rodríguez, A. 2002. Toros en México, Revista de Cultura, Empresa Pagés.

Secretaría de Turismo y Desarrollo Económico (SETyDE) 2015. Informe de actividades 2014-2015

Secretaría de Turismo del Estado de Tlaxcala (SECTURE) 2017. Informe de actividades 2016-2017

Secretaria de Turismo Federal (SECTUR)

2017. Quinto informe de labores 2016-2017. Recuperado de: http://www.sectur.gob.mx/wp-contents/ uploads/2018/09/QuintoInformeDeLaboresSectur2017.pdf, consultado diciembre 2018.

Terán, J.A. 2002. Arquitectura rural en México. Las haciendas de una región en Estudios sobre arquitectura iberoamericana

Torices, N. y Zurita E. 2003. La arquitectura agraria en la Provincia de Granada en Cortijos, Haciendas y Lagares en la Provincia de Granada, Consejería de Obras Públicas, Sevilla, España.

Yanes, G. y Ríos, S. 2014. Arquitectura virreinal: la hacienda poblana y su potencial turístico de desarrollo local, Fondo Mixto CONACYT-Gobierno del Estado de Puebla y El Colegio de Tlaxcala, A.C., México

\section{Notas}

1 Fundado en 1939, con fundamento y respaldo legal, con la encomienda de garantizar la investigación, protección, difusión y divulgación del patrimonio de México. Actualmente es responsable de 110 mil monumentos históricos, que datan de los siglos XVI y XIX, y de 29 mil zonas arqueológicas registradas en todo el país (página oficial del INAH).

2 Distintivo elaborado con listones trenzados de colores que identifica a la ganadería, se le coloca al toro antes de salir al ruedo.

3 Durante el sexenio de Cárdenas (1934-1940) se realizó el reparto agrario de 18 millones de has., de haciendas y ganaderías, dando origen al régimen de propiedad ejidal en México.

4 Denominación que otorga la Secretaría de Turismo mexicana a sitios cuyo patrimonio cultural es especialmente relevante, actualmente en México se cuenta con 121 Pueblos Mágicos.

Recibido: 